\title{
Does neuraxial anesthesia damage DNA as general anesthesia?
}

Astapenko D. ${ }^{1,2,3}$, Koščáková M. ${ }^{3,4}$, Zubáňová V. ${ }^{3,4}$, Kuchařová M. ${ }^{3,4}$, Štětina R. ${ }^{3}$, Černý V. ${ }^{2,3,5,6}$ and Zadák Z. ${ }^{3}$

1) Dept. of Anesthesiology, Resuscitation and Intensive Care Medicine, University Hospital Hradec Králové, Czech Republic

2) Faculty of Medicine in Hradec Králové, Charles University in Prague, Czech Republic

3) Centrum for Research and Developement, University Hospital Hradec Králové, Czech Republic

4) Faculty of Pharmacy in Hradec Králové, Charles University in Prague, Czech Republic

5) Dept. of Anesthesiology, Perioperative and Intensive Medicine, Masaryk Hospital in Ústí nad Labem, IPVZ, Czech Republic

6) Dept. of Anesthesia, Pain Management and Perioperative Medicine, Dalhousie University, Halifax, Canada

\section{Background}

DNA damage during general anesthesia has been well documented and it yields a significant burden to the patients, as it is iatrogenic damage. Data on neuraxial anesthesia are missing so far.

Our aim was to assess the amount of DNA damage in patients under general anesthesia (GA) and neuraxial anesthesia (NA) in a pilot study.

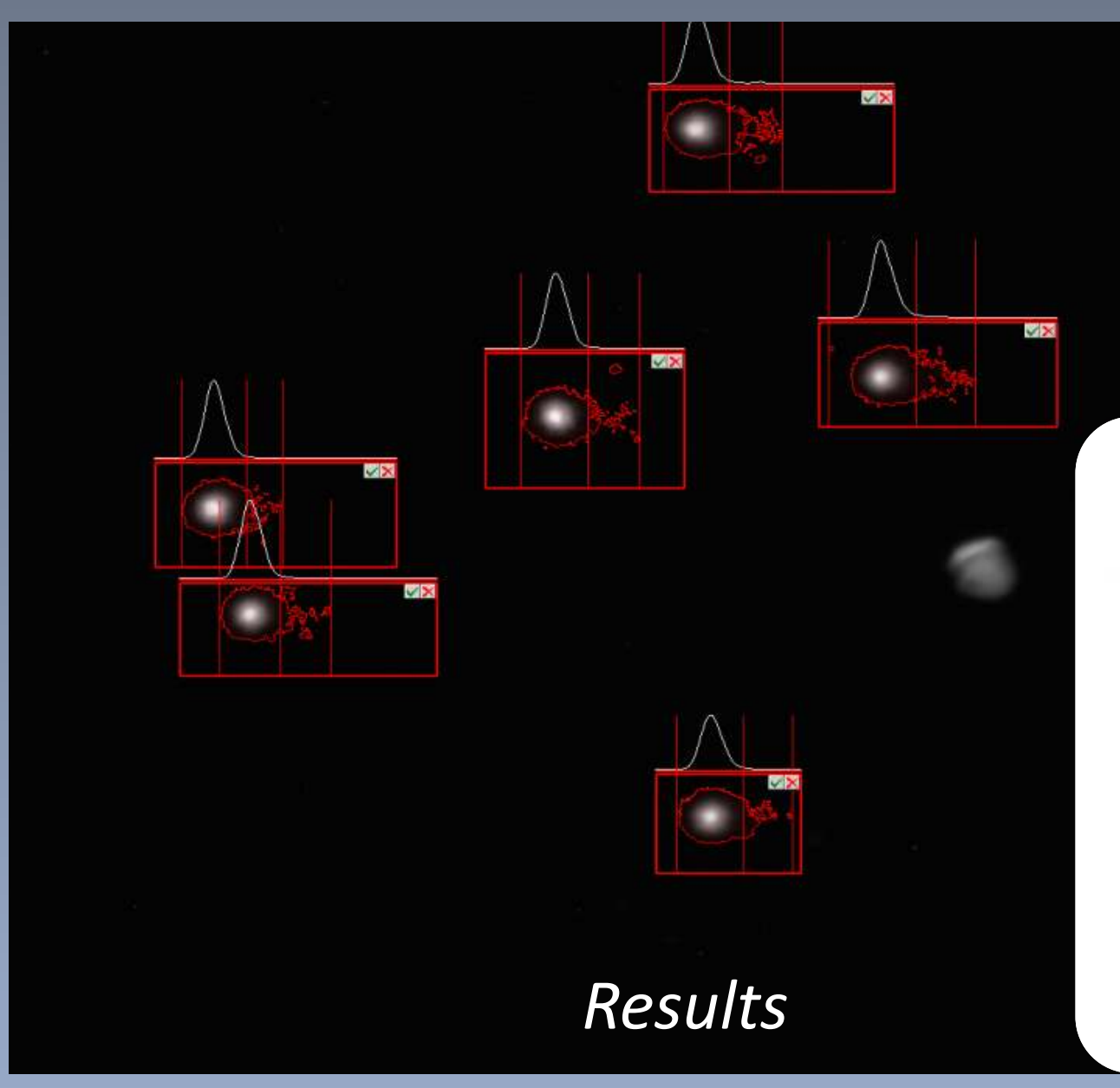

\begin{tabular}{|c|c|c|c|}
\hline & $\mathrm{GA}$ & $\mathrm{NA}$ & $\mathrm{p}$ value \\
\hline $\mathrm{MAP}[\mathrm{mm} \mathrm{Hg}]$ & 96 & 94 & 0,47 \\
\hline $\mathrm{HR}[\mathrm{BPM}]$ & 82 & 74 & 0,03 \\
\hline $\mathrm{SpO}[\%]$ & 98 & 96 & 0,002 \\
\hline $\mathrm{Hb}[\mathrm{g} / \mathrm{l}]$ & 116 & 142 & 0,0004 \\
\hline $\mathrm{Htc}[\mathrm{ratio}]$ & 0,33 & 0,42 & $<0,0001$ \\
\hline $\mathrm{Na}[\mathrm{mmol} / \mathrm{l}]$ & 139 & 140 & 0,53 \\
\hline $\mathrm{K}[\mathrm{mmol} / \mathrm{l}]$ & 4,3 & 4,2 & 0,54 \\
\hline $\mathrm{Cl}[\mathrm{mmol} / \mathrm{l}]$ & 102 & 104 & 0,27 \\
\hline $\mathrm{Gly}[\mathrm{mmol} / \mathrm{l}]$ & 6 & 5,6 & 0,29 \\
\hline $\begin{array}{c}\text { Duration of } \\
\text { anesthesia [min] }\end{array}$ & 199 & 109 & 0,001 \\
\hline
\end{tabular}

\begin{tabular}{|c|c|c|c|}
\hline & GA & NA & $p$ value \\
\hline $\begin{array}{c}\text { Gender } \\
\text { female }\end{array}$ & 19 & 15 & N/A \\
\hline male & 10 & 7 & 0,96 \\
\hline Age & 40 & 62 & 0,96 \\
\hline BMI & 28,4 & 27,6 & 0,0002 \\
\hline ASA I [\%] & 13 & 21 & 0,64 \\
\hline ASA II & 54 & 68 & 0,35 \\
\hline ASA III & 27 & 11 & 0,22 \\
\hline ASA IV & 6 & 0 & 0,25 \\
\hline
\end{tabular}

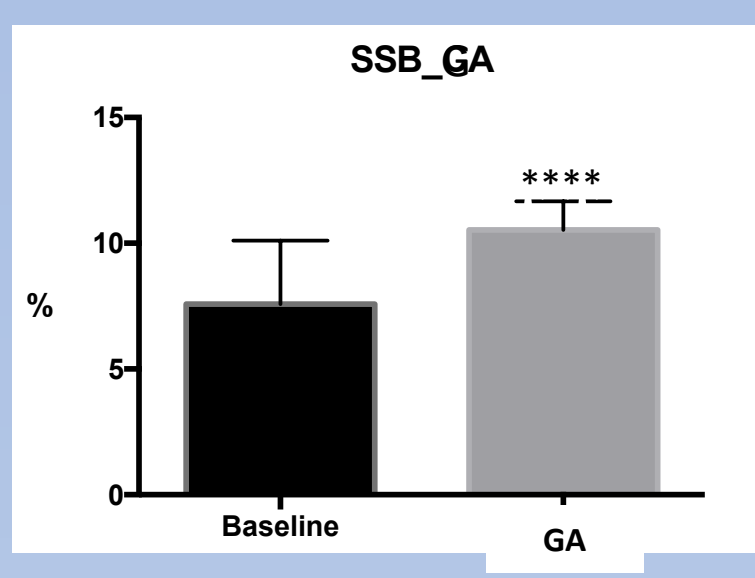

SSB_NA

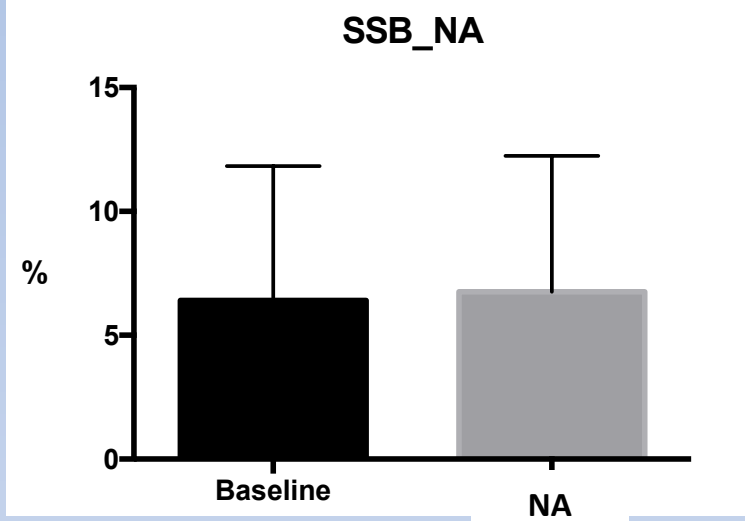

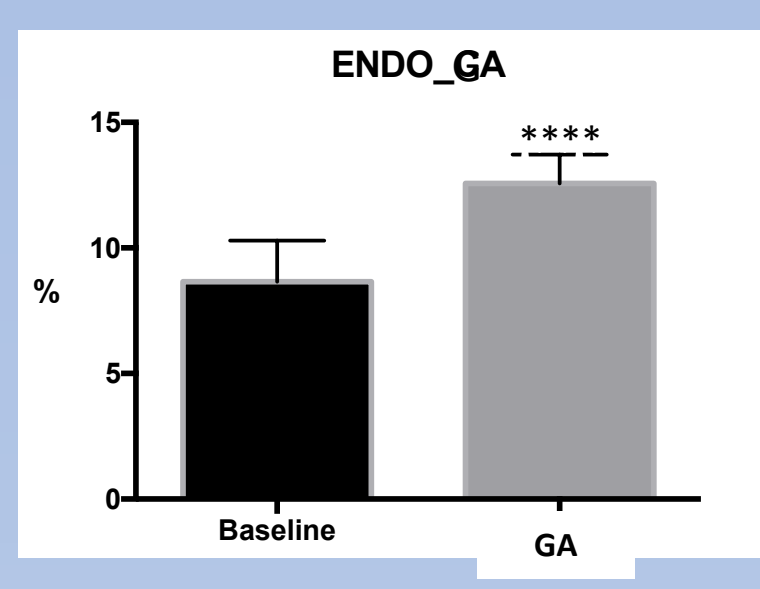

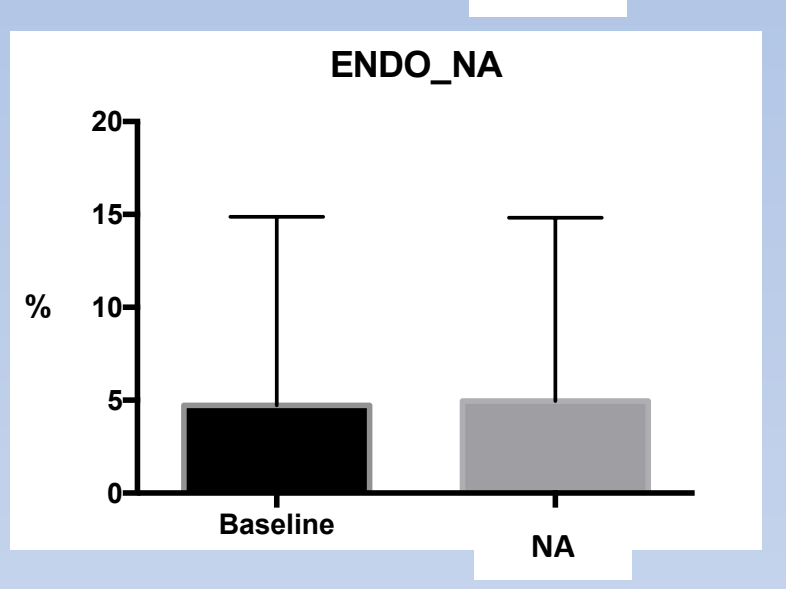

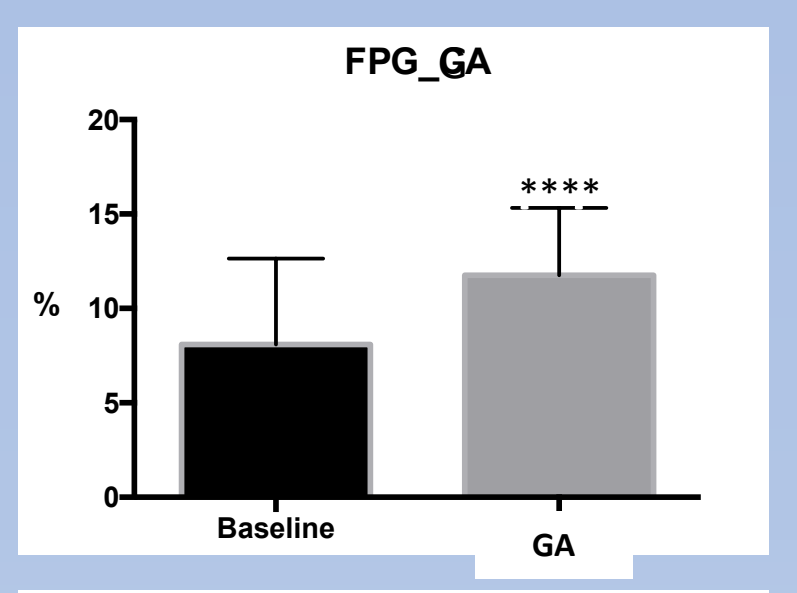

FPG_NA

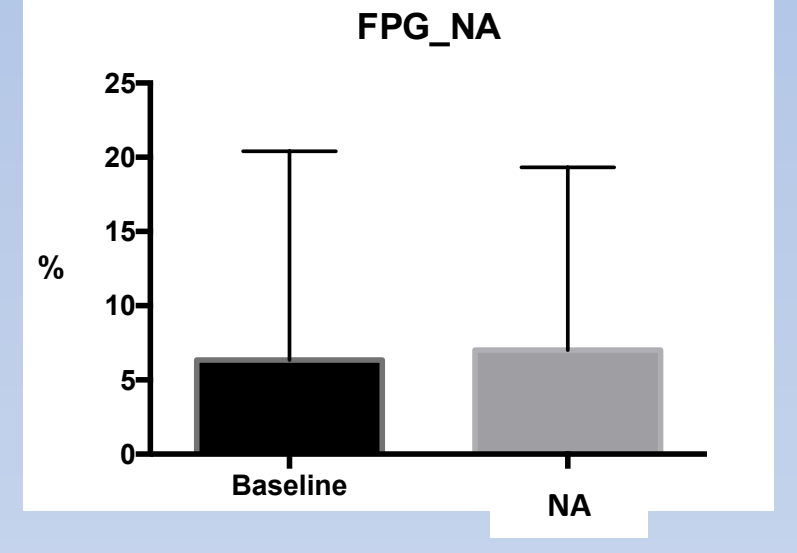

\section{Methods}

34 patients undergoing elective traumatology or orthopedic surgery on limbs and/or big joints were allocated to the GA or NA group.
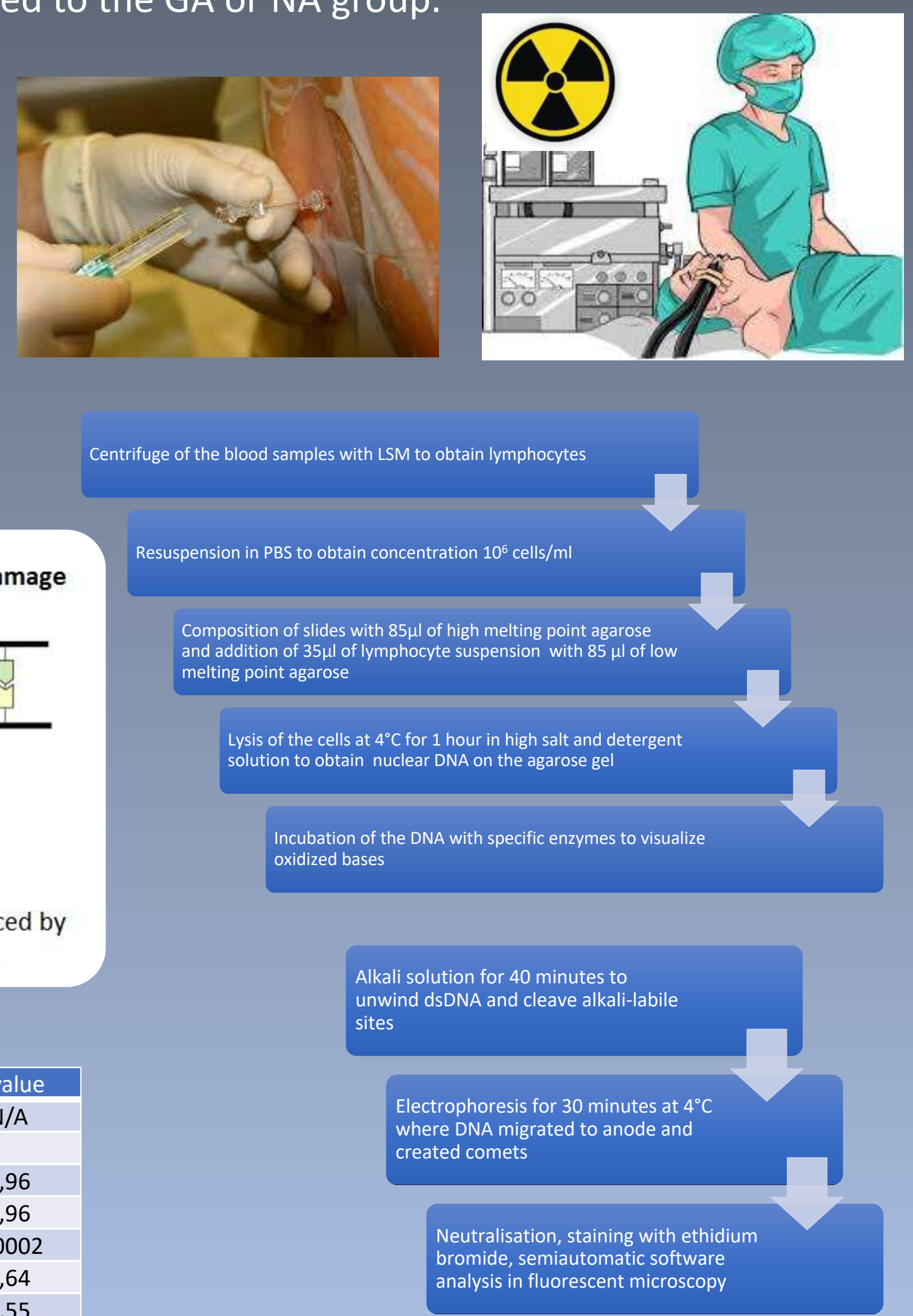

Conclusion

Our results declare that $\mathrm{GA}$ and $\mathrm{X}$-ray significantly damages nuclear DNA, unlike NA possibly due to the lower load of genotoxic agents and blockade of afferent signals from the site of surgery in traumatological and orthopedic patients.

Supported by MH CZ - DRO (UHHK, 00179906). 